\title{
The Role of Family in Children with PTSD after Natural Disasters
}

\section{Danchun Zhou}

School of Economics and Management, Lingnan Institute of Technology, Guangzhou, China

Email: zhoudance@126.com

How to cite this paper: Zhou, D.C. (2018) The Role of Family in Children with PTSD after Natural Disasters. Journal of Biosciences and Medicines, 6, 111-127.

https://doi.org/10.4236/jbm.2018.612011

Received: December 10, 2018

Accepted: December 24, 2018

Published: December 27, 2018

\begin{abstract}
Parents are the most important and reliable resource for their children to seeking for helps and support. Particularly in the aftermath of natural disasters, the role of family is considered to play an important and significant role in children with PTSD, either are risk factors or protective ones. In this paper, the literature in relation to the effects of family factors in children with PTSD are reviewed, with the aim of exploring both the risk and protective family factors associated with the PTSD symptoms in children. It is concluded that separation from families, parental psychopathology, and parent maladaptive coping strategies have been suggested o constitute risk factors, whereas positive parental emotionality, warm and open family environment have been found to be protective. Some critiques of PTSD concept, its cross-cultural validity, and assessment of children with PTSD are also revealed in this review.
\end{abstract}

\section{Keywords}

Family, Children, PTSD, Natural Disaster

\section{Introduction}

During the past century, there have been countless natural disasters, such as earthquakes, floods, hurricanes, tornadoes, bushfires, cyclones or tsunamis, having devastating consequences on millions of people all over the world, especially on the children of the communities [1] [2]. Children, at the age of $6-12$, may be affected not only by the tragedies but also by the surrounded circumstances, and may have some stress reactions, like displaying more overt aggression and destructiveness [3]. Not all children who suffer from such natural disasters develop post-traumatic stress disorder (PTSD) but there are some studies revealing that some kinds of children are vulnerable and are at risk of develop PTSD following natural disasters, such as those who have mental or emotional 
health problems before, who have antisocial characteristic, females, et [1] [3] [4] [5] [6] [7].

Although PTSD is a relatively new psychiatric disorder, first recognized in the Diagnostic and Statistical Manual of Mental Disorders (DSM-III) [8], the construct has already been around for really a long time and was not related to children and adolescents until the publication of DSM-III-R [9]. In the most comprehensive, current, and critical resources for diagnosis of PTSD in DSM-V [4], which specific to adults, adolescents, and children older than six years. The stressor criterion for PTSD was defined as "exposure to death, threatened death, actual or threatened serious injury, or actual or threatened sexual violence". And the person have to meet specific stipulations and symptoms from each of the following four clusters: "intrusion" (such as trauma-related intrusive memories, nightmares or flashbacks), "avoidance" (such as avoidance of trauma-related thoughts, feelings, people, or places), "negative alterations in cognitions and mood" (such as distorted and negative beliefs of oneself and the world, and the feelings of anger, fear or helpless) and "alterations in arousal and reactivity" (such as hypervigilance, aggressive or self-destructive behavior). Often, these signs and symptoms of disorders "last for more than one month" and "full diagnosis is not met until at least six months after the trauma".

It is worth mentioning that there are some changes of the definition of PTSD between DSM-IV [10] and DSM-V [4]. For example, PTSD was moved out of the anxiety disorders and was included in a new chapter on "trauma- and stressor-related disorders" and added a list of qualifying example to the definition of traumatic experience. In addition, people diagnosis of PTSD had four symptoms clusters in DSM-V, instead of three symptom clusters in DSM-IV, from "re-experiencing", "avoidance" and "arousal" to "intrusion", "avoidance", " negative alterations in cognitions and mood" and "alterations in arousal and reactivity". And some symptoms involved were accordingly added or modified. Furthermore, two subtypes ("PTSD in children younger than 6 years" and "PTSD with prominent dissociative symptoms") were included in DSM-V.: There is a research conducted by Gentes and colleagues [11] reported that according to these changes, the rate of PTSD using DSM-V was slightly lower than that of using DSM-IV.

It seems that a diagnosis of acute stress disorder (ASD), a second trauma-related diagnosis to describe responses to trauma events, is similar to those of PTSD and can predict subsequent PTSD [12] [13] [14]. But Scott and Stradling [14] also noted that the there are differences between ASD and PTSD. Specifically, one difference is that the duration of the diagnosis of ASD is within the first 30 days of a traumatic event, while PTSD diagnosis would be made until the posttraumatic symptoms were to persist at least a month. Another difference is that ASD emphasis more on dissociative symptoms. That means ASD requires a person experience dissociative symptoms, but not necessary have symptoms of intrusion, avoidance and disordered arousal. 
Children are more vulnerable than adults and can be affected negatively by PTSD [2]. For elementary school-aged children, unlike adults, they may not experience visual flashback or amnesia after the natural disasters, but experience "time skew" and "omen formation" [15]. That means the recollection of the traumatic events by these children may be in reverse order, and they believe that they themselves have the ability to recognize the warning signs and avoid future traumas. Furthermore, Hamblen [15] noted that the elementary school-aged children might also display posttraumatic play or reenactment of the trauma in play or drawings.

PTSD has tended to be the most primary psychological outcome assessed in children after natural disasters, which sometimes comes with depression and other anxiety disorders. For example, three months after the earthquake, a school-based survey found that in a sample, $4.3 \%$ of the students were found to have PTSD [16]. In a review of studies on natural disasters, La Greca and Prinstein [17] noted that only $5 \%$ to $10 \%$ of children and adolescents may meet criteria for a full diagnosis of PTSD. Information we have on prevalence of PTSD in children comes from a study called British National Survey revealed that only $0.4 \%$ of $11-15$ years olds were diagnosed with PTSD [3]. In China, Li and colleagues [1] also revealed that the rate of PTSD in school-aged children after flooding in Hunan is $4.7 \%$ in 1998. The different rate of PTSD across studies depend on different methodology [3] [18], such as various measures (DSM-III, IV or V), assessment methods, time of assessment, the size of sample, country differences, etc.

For children, several instruments used in assessing the effect of trauma are in uses. Specially, the most common and widely used measure is the Child PTSD Reaction Index (CPTSD-RI) [19]. It is a 20-item scale firstly designed according to DSM-III criteria, and being modified based on DSM-IV, to better assess symptoms of children following traumas. Also, many other instruments, like the Clinician Administered PTSD Scale for Children (CAPS-C) [20], the child PTSD Symptom Scale (CPSS), are also common used for children.

This current study aims to explore the question of whether the posttraumatic role of family after natural disasters is associated with the adjustment of children with PTSD and what the factors are. For me, what makes PTSD interesting to me is that it has a disorder - causing source-traumatic event - and this situation is likely to disrupt sufferers' life, which makes them unable to control. We should give more attention to these people who suffer from PTSD and improve their mental health, especially for the children. Children are vulnerable groups and we should protect them and be responsible for them. And the events scheduled I decide are after natural disasters because among multiple categories of variables which affect children's adjustment of their PTSD symptoms-including pre-disaster child characteristic, disaster exposure and post-disaster environment (including family environment)-only the post-disaster environment can be changed. Working towards in this field will help us to treat children and families more effectively. 


\section{Materials and Method}

The electronic database used for this literature review was the Social Sciences Citation Index (1970+) of PaoYue-Kong Library, the Hong Kong Polytechnic University, with full text. Only three keywords, i.e., "children with PTSD", "Family" and "natural disasters" were used and 49 articles could be found. To get more research, sometime the keyword of "family" can be replaced with a word of "parent" and 21 more articles could be found. For the purpose of this review, there are several inclusion criteria by which studies will be selected. The first criterion for including any article was that children within each study included in this review had to meet the DSM-IV criteria for PTSD and to be between the ages of 6 to 12 years old. The second criterion was that the research must be conducted after natural disasters, aiming to study the post-disaster family factors. Additionally, the study had to be available in English language. After the title and abstract of each of the 60 articles were reviewed, the articles were narrowed down to 24 for review in this paper.

\subsection{Research on the Role of Family in Children with PTSD after Natural Disasters}

In general, children spend most of their times staying with their familial context following traumatic events. Unlike adults who have the cognitive and emotional maturity, children's emotional regulation, responses to stress, and strategies to cope with disasters are influenced a lot by their parents [21] [22]. For the children with PTSD symptoms, the role of family plays a much more important and significant role than others and is closely associated with the children's development, expression, and maintenance of psychopathology [23] [24]. Recently, in the field of post-disaster research, many studies have examined the impact of the role of family, with the consensus being that there may be many different roles of family, such as the role of parent psychopathology and parenting variables, that are closely associated with different influence of their children's PTSD symptoms following natural disaster [25] [26] [27]. The risk and protective factor of the role of family can be analyzed in detail as the following.

\subsection{Risk Family Factors Associated with PTSD in Children}

It has been proven through many most recent researches on risk factors for the development of PTSD in children; there are three important and significant risk factors, which result in more PTSD symptoms in their children. These are separation from families, parental psychopathology and parent maladaptive coping strategies [25] [26].

\subsection{Separation from Families}

Some children may suffer from separation from their parents following natural disaster, especially when they have to evacuate in front of natural disaster while their parents stay behind being in defense of their home or helping with the re- 
lief work. It also occurs when earthquake striking or flood waters com rushing warning and they are studying in school while their parents are working at different places, which makes them cannot be together and have to separate [2]. In this case, separation from one or more family members may cause far more anxiety and uncertainty, sleeping difficulties, hypervigilance and thus get a higher level of PTSD symptoms of children [2] [27] [28]. For example, McFarlane [27] found that after a devastating bushfire, some parents would send their children to their relatives to live in a few days and then they themselves could cope with damage. However, after 26 months, among children and their parents who still live separately, they have a more risk of development of PTSD symptoms because of their insistent worry of their parents (separation may not be the only one factor).

\section{Parental Psychopathology}

It has been proven through many researches that parental distress and PTSD had a detrimental effect on their children's adjustment problems of PTSD in the aftermath of traumatic events [23] [26] [29]-[35]. For example, as for the maternal psychology, a recent study of children with PTSD revealed that maternal psychological distress and PTSD had a moderating effect on the relationship between child hurricane exposure and children's adjustment problems following hurricane Katrian [33]. There are many researches on PTSD in children supported this statement [26] [30] [34]. Interestingly, Kilic, Ozguven and Sayil [30] assessed 35 families who lived in "tent city" for their mental health problems, particularly for PTSD, depression and state and trait anxiety, after the 1999 earthquake in Turkey. The research exploring the effects of fathers' psychopathology on their children with PTSD showed that fathers, who were afflicted with PTSD, displayed irritability and detachment and resulted in further exacerbation of PTSD symptoms in their children [30].

When living in a family of both parents with PTSD, there will be more risk for the children to deteriorate of their PTSD symptoms [1] [34] [37]. Bernadon \& Pernice-Duca [34] reported that parental PTSD, showing avoidance or hyperarousal behavior, might be overwhelmed by themselves and thus overlook their children's anxieties, fear, or other symptoms, and also might cause themselves to be more reactive and impetuous when getting along with their children, which predicted higher level of PTSD symptoms in their children. Another research conducted by McFarlane [31] found that parental distress exacerbated their children's PTSD symptoms following the 1983 Australian bushfire, which was a more important and stronger predictor than the direct exposure to the natural disaster for their children. And when both parents were overwhelmed by their intrusive memories of the natural disasters and feeling fear, they might share the experience with their children and reinforce the message and image of the traumatic events and made the children hard to recover. What's more, Li and colleagues [1] pointed out that the parental distress and PTSD can lead to their 
feeling of fear, afraid, sleeping difficulties, avoidance of thought and not willing to discuss the trauma, etc., which would indirectly have bad effect on their parenting practice, relationship with their children and their family atmosphere, which in turn, may have the potential to moderate the PTSD in children.

It is also worth to mention that McFarlane [31] noted in his study that the younger a child, the stronger influence by their parents' psychological distress and PTSD problem would have after the natural disasters. What's more, Birmes and colleagues [38] claimed that a child, being female, living in a family of 3 or more children, staying with her mother who suffered from high post-traumatic stress symptoms, would get a high level of PTSD in the aftermath of traumatic events.

\section{Parent Maladaptive Coping Strategies}

It is reported by many researchers that parents will also be affected by the same disaster, so their support and assistance to their children will be reduced accordingly, and thus their maladaptive coping responses and less support may predict increased child PTSD symptoms after the natural disaster[6] [18] [24] [27] [30] [38] [39] [40] [41] [42]. Here, the common maladaptive coping responses are always in the form of overcompensation (e.g., aggression, passive-aggressiveness, dominance), surrender (e.g., give in, dependent) and avoidance (e.g., addictive self-soothing, coping through dissociation, denial, unavailability to discuss the disasters).

As for overcompensation, A research conducted by Kelley and colleagues[40] also revealed that after hurricane Katrina, parents are more likely to use maladaptive coping strategies, such as corporal punishment, which have a negative influence on their children's adjustment of PTSD symptoms at the 4 - 7 months and 14 - 17 months post-disaster time points. Similarly, Kilic, Ozguven and Sayil [30] pointed out that the fathers becoming irritable and always blaming, criticizing, or even using corporal punishment, like hitting their children with a belt or slap their children after the Turkish earthquake, would increase their children's anxiety and horror about the trauma and have a negative effect on their children and thus increase the development of their children's PTSD symptoms. These are consistent with the other research [39]. What's more, Kilic, Ozguven and Sayil also noted that the parental conflict about how to respond, complaining each other, and domestic violence following adversity exposure made it less able to provide the usual safe, secure, stable and consistent environment for their children and thus resulted in more PTSD symptoms in their children [30]. Similarly, studying a sample of families who were affected by the Hurricane Andrew, Wasserstein and La Greca [35] found the more conflicts between parents at post-hurricane time, the more severe symptoms would be found in their children.

In addition, current findings suggest that the role of excessive parental control, overprotection and infantilization of children can exacerbate risk of child 
PTSD. Kelley and colleagues [40] noted that excessive parental control and employing more child routines for a long time after hurricane Katrina were associated with child routines and would increase their children's symptoms of hypervigilance and place their children at greater risk for PTSD. This claim is also supported by Khamis [43]. Although Khamis found that there is no significant difference in parental support following, including love, caring, help, gifts, money etc., between children with and without PTSD. However, family ambiance seemed to serve as a significant predictor of children with PTSD, with high levels of PTSD symptoms in children was found in harsh disciplining environment after traumatic events, including natural disasters. On the other hand, when parents provide an overprotective environment and infantilize their children for a long time after natural disasters, it may be harmful for their children's mental health, reinforce the avoidance behaviors of their children, leading to withdrawal of children, and thus be an obstacle in their recovery process [24] [27] [38] [39] [42].

As for surrender, Eksi and colleagues [18] reported that following the earthquake, if parents showed the signs of giving in or dependent, like accepting the life and became self-absorbed with crying, wailing or even praying loudly, these reactions would be all observed by their children, which would make them have difficult to sleep or have frightening dreams without recognizable content and be a risk factor influencing their children's responses to disaster and predict increased child PTSD symptoms.

As for avoidance, a recent research conducted by Kelley and colleagues [40] claimed that when parents negatively cope with the hurricane Katrina, like using drugs or alcohol to be addictive self-soothing and avoiding the fact, they would be less able to provide support to their children, overlook their children's needs and fail to address their needs in time, and thus increase their children's risk for PTSD symptoms. Additionally, parents being detached, numbing after earthquake would be associated with poor adjustment in children's PTSD symptoms [30]. And if parents deny the traumatic events, under react and minimize danger following a disaster, it would also exacerbate the risk of their children's PTSD symptoms [42]. Moreover, when faced in natural disasters, parents may feel distress and may be unwilling to discuss the disasters and its aftermath, thinking it as a way to better protect their children, or because of the cultural taboos against such discussion. And thus result in the unavailability of communication and predict increased child PTSD symptoms [2] [44] [45] [46]. For example, a research conducted by Garfin and colleagues [44] noted that children's perception of parent unwillingness and unavailability to discuss the earthquake would be positively associated with their ongoing earthquake-related worry, which would finally exacerbate the risk of PTSD in children.

\section{Protective Family Factors Associated with PTSD in Children}

In the face of natural disasters, parents are also the victims who have to bear a lot 
of pressure and burden, including rebuilding their homes or other damage repair. At some point, they may have a hard time to handle their own emotions and feel it difficult to provide adequate care, concern, interest and support for their children [14]. However, empirical studies have shown that there are two important and significant protective factors, which may play an important role in alleviating PTSD symptoms in children. These are Positive parental emotionality and Warm and open family environment [40] [47] [48].

\subsection{Positive Parental Emotionality}

There is evidence that parents' positive emotional reaction to natural disasters may play an important role in alleviating PTSD symptoms in their children [47] [49]. A literature review of PTSD in children and adolescents reported by Davis \& Siege [47] suggest that positive parental emotionality in the aftermath of disasters, such as being in control and remain calm, may assuaging their children's fears and make them feel protected and secures, and thus decrease the likelihood of maladjustment and serve as an important mediator of PTSD for their children. This notion is consistent with the other study reported by Gil-Rivas, Holman \& Silver [49]. They reported that the more positive their parents' attitude and emotion, the more positive affect children would have after at one year after natural disaster, and the more positive adjustment in children's PTSD symptoms.

\subsection{Warm and Open Family Environment}

It has been proven through many researches that warm and social support, especially from parents, such as family involvement, open and communicative family atmosphere, availability to discuss the traumatic events and problems in the short-term aftermath, may contribute to positive affect among children and serve as protective factor associated with more positive adjustment in children's PTSD symptoms [40] [48] [50] [51] [52]. For example, a research conducted by La Greca and colleagues [50] reported that parents' empathic acceptance of their children's discussion of feelings and concerns about the hurricane Andrew, listening to sound of their children's heart, sharing their perceptions and experience of trauma to this degree, could better help their children understand and interpret what was happened and objectively appraise the severity of the hurricane, and thus provide their children with guidance about coping solutions and may be protective against their children's PTSD. Similarly, within the context of hurricane, another research conducted by Kelley and colleagues [40] suggested that parent availability to discuss the trauma, willing to listen to and encourage their children to supplant the traumatic event with a constructive and positive thought, as well as high quality communication with providing fast and effective conflict resolution to their children, could contribute to their children's better understand of the trauma itself, facilitate the disclosure of feelings and thoughts of their children and accordingly alleviate PTSD in their children. Within warm 
and open family environment, parents may be able to provide support to their children and help them to reduce their likelihood of maladjustment of PTSD symptoms [52].

\section{Discussion}

The 24 research reviewed in this paper indicate that parents are the most important and reliable resource for their children to seeking for help and support. Particularly in the aftermath of natural disasters, the role of family is considered to play an important and significant role in children with PTSD, either are risk factors or protective ones. Among all the family factors, the separation of children and their parents makes the children suffer from more anxiety, uncertainty and increased PTSD symptoms. Additionally, parents, especially mothers, who are under distress or suffer from PTSD will in some way "transmitted" to the children, causing the higher level of their children's PTSD symptoms. Meanwhile, in front of natural disasters, the parent maladaptive coping responses and less support, such as corporal punishment, blaming, parental conflict, overprotection, overly control, harsh discipline, giving in, be addictive self-shooting, and unwilling to discuss the trauma et., also become major risk factor spredicting increased PTSD symptoms in their children. Conversely, if the parents can remain in control and keep calm in the face of disasters, or can create an open and warm family atmosphere, have availability to discuss the trauma and support; care for their children, the PTSD symptoms in their children can be improved to some extent. Interestingly, a research conducted by Wasserstein and La Greca [35] not only pointed out that higher perceived parental conflict was greatly associated with higher PTSD symptoms in Hispanic children after hurricane Andrew, but also noted that this kind of association is not exist in White and African American children, and that Hispanic children showed more PTSD symptoms than did White children among high parental conflict children. However, it is worth mention that there is one exceptional research in this field. In contrast to McFarlane [27] and Green and colleagues [26], the one exception was a recent study reported by McDermott \& Cobham [21], they found that after natural disasters, family resilience, including parental behavior control, communication between family members, parental emotional responses and parent coping strategies, was related to children's anxiety and depressive symptoms, but not to their PTSD symptoms.

\subsection{Critique of PTSD Concept}

However, until now, psychiatrist and psychologists have been in a long and fierce discussion and debating over the public health value of the concept of PTSD without reaching any agreement [53]. On one hand, the psychiatrics and psychologists of the American Psychiatric Association perceived PTSD as a "non-contingent entity", emphasizing the "reality" of PTSD [54]. On the other hand, some other psychiatrist challenge and deny the validity of the concept of 
PTSD. They claimed that PTSD was one example how society created rather than discovered a mental illness and too much focus on PTSD may result in rushing into traumatic settings to study PTSD and unintentionally overlook the important and significant task of the understanding the natural causes and helping protect and improve people's mental health in the first stage [55]. What's more, The WHO Report on "Mental Health in Emergencies" (WHO, 2003) states that the best way to solve the acute mental health problems during the stage of acute emergency is to consistently adhere to the principles of "psychological first aid". After that, in the next stage of reconsolidation, a variety of educated social workers, aid workers and professional health staffs are suggested to provide supervised psychological first aid, emotional support, identification and care for the severe mental health problem, such as PTSD. In consistent with WHO, the Inter-Agency Standing Committee (IASC, 2007) claims that help and protect people's mental health and psychosocial well-being is considered the most important and critical step in the process of an emergency. Another level of critique of the PTSD category involves in its defect in designing the questionnaires [56]. Firstly, it is a fact that not all People can understand the question the same way as the researcher does. Additionally, various kinds of psychological conditions not always show with similar mental symptoms, and not all cognitive or affective responses to distress are forms of disorder or psychopathology. No matter how much the concept of PTSD is criticized, it indeed provide an over vational framework for researchers to study the negative impact of traumatic and distress and really make a great contribution to psychiatry.

It is also worth mention that for the past two decades, the International Classification for Disease, recently in its 10th edition (ICD-10), also contain a diagnosis of PTSD, but different from that of DSM-V [57]. For example, for the proposed ICD-11 PTSD diagnosis, the criteria focus on only six items- two re-experiencing (nightmares and flashback), two avoidance (of thoughts and feelings, and of places, people and activities), and two hyperarousal (increased startle and hypervigilance) [57] [58]. Compared to the definition of PTSD in DSM-V, the ICD-11 proposal would lack tree intrusion symptoms, all seven of the "negative alterations in cognitions and mood" symptoms, and four of the "alterations in arousal and reactivity" symptoms. Also, this proposal adds a new complex PTSD (CPTSD), many symptoms of which are showed in the definition of PTSD in DSM-V [57]. This system is used and adopted by the WHO and the U.S. Health Insurance Portability and Accountability Act (HIPPA).

\subsection{Critique Cross-Cultural Validity of PTSD}

At the same time, PTSD is criticized by its cross-cultural universality. In contrast to some notion claimed by some psychiatrists and psychologist that PTSD is a "universal and multicultural effective to use Western clinical and psychosocial approach to treat and cure traumatic distress ", there are some other experts arguing that PTSD is the particular products of all ethnic cultures in specific back- 
ground, and it will be problematic especially considering the wide-range of social-cultural backgrounds. They think that mental illness perception and symptoms manifestation of people in the context of different cultural settings are different, including the indigenous expression and idioms of distress, and thus the PTSD construct cannot stand up to the test of standardization. For example, some researcher argued that PTSD as a Western cultural construction, and not all its criteria are applicable to that of other countries, such as flashbacks [54]. There are some other research suggested that although PTSD can correctly describe some universal trauma response characteristic, its clinical utility lags behind that of more local forms of expressing trauma-related psychopathology, including cultural syndromes [57]. Because these more localized expression is more "experience-near", patients can use their local language and interpretations to convey their understanding of their own mental illness, and the clinicians can get more accurate information to better measure patient's illness presentation, to better communicate with the sufferers, to better understand and care for them, so as to enhance their physician-patient relationship and treatment adherence, leading to greater clinical effectiveness [54]. In china, we can find lots of research on PTSD, however, the PTSD psychiatric diagnosis and its assessment tools are mostly based on DSM and ICD criteria, including Chinese version of the Diagnostic Interview Schedule (DIS), the International Diagnostic Interview (IDI), the Structured Clinical interview for DSM-IV axis I diagnosis (SCID-I), and the Chinese version of the Children's Interview for Psychiatric Syndromes (ChIPS). Most research using these measures as a tool to assess the children's response towards traumatic events without consideration of cross-cultural differences and there are growing uncertainties regarding the validity of Western concept and its assumption of psychosocial trauma models, the application of its treatment (Wilson \& Tang, 2007).

\subsection{Critique of Assessment of PTSD in Children}

In assessing PTSD symptoms for children reported by their parents, recent research suggested that parents may be widely underestimating children's the degree of distress symptoms and responses towards to disasters [3]. It has been noted that children are sensitive to their parent's responses and reactions and some of they may prevent themselves from discussing or talking about the traumatic events, their feelings and thoughts to avoid adding much more mental distress for their parents, who have been badly affected and upset. In addition, it is much easier for parents to ignore their children's distress when children were engaging in play activities shortly after traumatic events. They may think their children are symptom-free or they will not participate in play, drama or other activities. However, their children are often observed and recognized reenacting the trauma frequently when they are playing. Thus, when assess the PTSD symptoms of children, children's own report have to be worth of serious consideration, although parents' report are also important. 
But there are also some other problems when it comes to measuring PTSD symptoms dependent on self-reports by children themselves using DSM-V. One problem is that children are not mature enough to understand and appreciate some descriptions revealed on the DSM-V symptoms [14]. For example, when it comes to the notion of a foreshortened future, some of them may feel it much easier to understand when it is reframed to whether they have greater concerns about mortality. Also, it is common that young children were found less emotional numbing, and it is difficult for them to report avoidance reactions, which are not applied so much to ICD-10 diagnosis, because of their low level of cognitive introspective ability. These situations lead to some difficulties to determine whether the children are in compliance with avoidance criterion in DSM-V (3). What's more, it is also difficult to make some determinations in respect to whether they are experiencing emotional numbing. Scott and Stradling [14] also suggested that in accessing PTSD symptoms of children, some important, significant but often-neglected signs should be noted, such as children regressing, recommencing thumb sucking or bed wetting, or dysfunction in school work.

\section{Conclusion}

In the future, on one hand, more Chinese research on children with PTSD deserve more attention for they are vulnerable groups and can be affected negatively by PTSD, their symptoms have something different from adults. What's more, it is necessary to establish a platform for trauma clinicians and researchers so that they can not only better understand the Western assessment tools and treatment protocols, but also working together to develop a local trauma models. In the meantime, findings about Chinese children trauma survivors should be spread to areas of the country, and even the world, to have a better understanding of cross-cultural context about trauma and its mental health applications (Wilson \& Tang, 2007).On the other hand, as a counselor, it Is worth noting that parents may be widely underestimating children's the degree of distress symptoms and responses towards to disasters, so children's own report have to be worth of serious consideration. After we better understanding that the parental psychopathology has a detrimental effect on their children with PTSD, we should help and improve parents' mental health when we treat children. At the same time, knowing that parents' creation of an open and warm family atmosphere can serve as a protective factor associated with more positive adjustment in their children's PTSD, we should help and train their parents how to answer questions raised by children honestly, how to use an age-appropriate manner to tell their children what happen, how to listen more effectively to their children's concerns, how to get their kids to understand some distress is normative and find hope towards trauma events [14].

\section{Conflicts of Interest}

The author declares no conflicts of interest regarding the publication of this paper. 


\section{References}

[1] Li, X.H., Huang, X., Tan, H.G., Liu, A.Z., Zhou, J. and Yang, T.B. (2010) A Study on the Relationship between Posttraumatic Stress Disorder in Flood Victim Parents and Children in Hunan, China. Australian and New Zealand Journal of Psychiatry, 44, 543-550.

[2] Mohay, H. and Forbes, N. (2009) Reducing the Risk of Posttraumatic Stress Disorder in Children Following Natural Disasters. Australian Journal of Guidance and Counselling. 19, 179-195. https://doi.org/10.1375/ajgc.19.2.179

[3] Dyregrov, A. and Yule, W. (2006) A Review of PTSD in Children. Child and Adolescent Mental Health, 11, 176-184. https://doi.org/10.1111/j.1475-3588.2005.00384.x

[4] American Psychiatric Association (2013) Diagnostic and Statistical Manual of Mental Disorders. 5th Edition, American Psychiatric Press, Washington DC.

[5] Giannopoulou, I., Strouthos, M., Smith, P., Dikaiakou, A., Galanopoulou, V. and Yule, W. (2006) Post-Traumatic Stress Reactions of Children and Adolescents Exposed to the Athens 1999 Earthquake. Eur. Psychiatry, 21, 160-166. https://doi.org/10.1016/j.eurpsy.2005.09.005

[6] Norris, F.H., Friedman, M.J., Watson, P.J., Byrne, C.M., Diaz, E. and Kaniasty, K. (2002) 60,000 Disaster Victims Speak: Part I. An Empirical Review of the Empirical Literature, 1981-2001. Psychiatry. Interpersonal and Biological Processes, 65, 207-239. https://doi.org/10.1521/psyc.65.3.207.20173

[7] Osofsky, H.J., Osofsky, J.D., Kronenberg, M., Brennan, A. and Hansel, T.C. (2009) Posttraumatic Stress Symptoms in Children after Hurricane Katrina: Predicting the Need for Mental Health Services. American Journal of Orthopsychiatry, 79, 212-220. https://doi.org/10.1037/a0016179

[8] American Psychiatric Association (1980) Diagnostic and Statistical Manual of Mental Disorders. 3rd Edition, American Psychiatric Press, Washington DC.

[9] American Psychiatric Association (1987) Diagnostic and Statistical Manual of Mental Disorders. 3rd Revision Edition, American Psychiatric Press, Washington DC.

[10] American Psychiatric Association (1994) Diagnostic and Statistical Manual of Mental Disorders. 4th Edition, American Psychiatric Press, Washington DC.

[11] Gentes, E.L., Dennis, P.A., Kimbrel, N.A., Rissling, M.B., Beckham, J.C., VA Mid-Atlantic MIRECC Workgroup and Calhoun, P.S. (2014) DSM-5 Posttraumatic Stress Disorder: Factor Structure and Rates of Diagnosis. Journal of Psychiatric Research, 59, 60-67. https://doi.org/10.1016/j.jpsychires.2014.08.014

[12] Bryant, R.A. and Harvey, A.G. (1998) The Relationship between Acute Stress Disorder and Posttraumatic Stress Disorder: A Prospective Evaluation of Motor Vehicle Accident Survivors. Journal of Consulting and Clinical Psychology, 66, 507-512. https://doi.org/10.1037/0022-006X.66.3.507

[13] Marshall, R.D., Spitzer, R. and Liebowitz, M.R. (1999) Review and Critique of the New DSM-IV Diagnosis of Acute Stress Disorder. Am J Psychiatry, 156, 1677-1685.

[14] Scott, M.J. and Stradling, S.G. (2006) Counseling for Post-Traumatic Stress Disorder. 3th Edition, SAGE publications Ltd., London.

[15] Hamblen, J. (2003) National Center for PTSD. http://www.ncptsd.va.gov/ncmain/ncdocs/fact_shts/fs_children.html

[16] Roussos, A., Goenjian, A.K., Steinberg, A.M., Sotiropoulou, C., Kakaki, M., Kabakos, C., Karagianni, S. and Manouras, V. (2005) Posttraumatic Stress and Depres- 
sive Reactions among Children and Adolescents after the 1999 Earthquake in AnoLiosia, Greece. Am I Psychiatry, 162, 530-537. https://doi.org/10.1176/appi.ajp.162.3.530

[17] La Greca, A. and Prinstein, M.J. (2002) Hurricanes and Earthquakes. In Helping Children Cope with Disasters and Terrorism. American Psychological Association, Washington DC. https://doi.org/10.1037/10454-005

[18] Eksi, A., Braun, K.L., Ertem-Vehid, H., Peykerli, G., Saydam, R., Toparlak, D. and Alyanak, B. (2007) Risk Factors for the Development of PTSD and Depression among Child and Adolescent Victims Following a 7.4 Magnitude Earthquake. International Journal of Psychiatry in Clinical Practice, 11, 190-199. https://doi.org/10.1080/13651500601017548

[19] Pynoos, R.S., Frederick, C., Nader, K., Arroyo, W., Steinberg, A., Eth, S., Nunez, F., and Fairbanks, L. (1987) Life Threat and Posttraumatic Stress in School-Age Children. Archives of General Psychiatry, 44, 1057-1063. https://doi.org/10.1001/archpsyc.1987.01800240031005

[20] Nader, K., Blake, D.D., Kriegler, J.A. and Pynoos, R.S. (1994) Clinician-Administered PTSD Scale for Children (CAPS-C) UCLA Neuropsychiatric Institute and Hospital/National Center for PTSD.

[21] McDermott, B.M. and Cobham, V.E. (2012) Family Functioning in the Aftermath of a Natural Disaster. Biomed Central Psychiatry, 12, 55. https://doi.org/10.1186/1471-244X-12-55

[22] Repetti, R.L., Taylor, S.E. and Seeman, T.E. (2002) Risky Families: Family Social Environments and the Mental and Physical Health of Offspring. Psychological Bulletin, 128, 330-366. https://doi.org/10.1037/0033-2909.128.2.330

[23] Bernardon, S. and Pernice-Duca, F. (2010) A Family Systems Perspective to Recovery from Posttraumatic Stress in Children. The Family Journal: Counseling and Therapy for Couples and Families, 18, 349-357. https://doi.org/10.1177/1066480710376618

[24] Bokszczanin, A. (2008) Parental Support, Family Conflict and Overprotectiveness: Predict in PTSD Symptom Levels in Adolescents 28 Months after a Natural Disaster. Anxiety Stress and Coping, 21, 325-335. https://doi.org/10.1080/10615800801950584

[25] Foy, D.N., Madvig, B.T., Pynoos, R.S., and Camilleri, A. (1996) Etiologic Factors in the Development of post Traumatic Stress Disorders in Children and Adolescents. Journal of School Psychology, 34, 133-145. https://doi.org/10.1016/0022-4405(96)00003-9

[26] Green, B.L., Korol, M., Grace, M.C., Vary, M.G., Leonard, A.C., Gleser, G.C. and Smitson-Cohen, S. (1991) Children and Disaster: Age, Gender, and Parental Effects on PTSD Symptoms. Journal of the American Academy of Child and Adolescent Psychiatry, 30, 945-951. https://doi.org/10.1097/00004583-199111000-00012

[27] McFarlane, A.C. (1987a) Family Functioning and Overprotection Following a Natural Disaster: the Longitudinal Effects of Post-Traumatic Morbidity. Australian and New Zealand Journal of Psychiatry, 21, 210-218. https://doi.org/10.3109/00048678709160914

[28] Vogel, J. and Vernberg, E.M. (1993) Children's Psychological Responses to Disaster. Journal of Clinical Child Psychology, 22, 470-484. https://doi.org/10.1207/s15374424jccp2204_7

[29] Jones, R.T., Ribbe, D.P., Cunningham, P.B., Weddle, J.D. and Langley, A.K. (2002) Psychological Impact of Fire Disaster on Children and Their Parents. Behavior 
Modification, 26, 163-186. https://doi.org/10.1177/0145445502026002003

[30] Kilic, E.Z., Ozenguven, H.D. and Sayil, I. (2003) The Psychological Effects of Parent Mental Health on Children Experiencing Disaster: The Experience of the Bolu Earthquake in Turkey. Family Process, 42, 485-495. https://doi.org/10.1111/j.1545-5300.2003.00485.x

[31] McFarlane, A.C. (1987b) Posttraumatic Phenomena in a Longitudinal Study of Children Following a Natural Disaster. Journal of the American Academy of Child and Adolescent Psychiatry, 26, 764-769. https://doi.org/10.1097/00004583-198709000-00025

[32] Ruestemli, A. and Karanci, A.N. (1996) Distress Reactions and Earthquake-Related Cognitions of Parents and Their Adolescent Children in a Victimized Population. Journal of Social Behavior and Personality, 11, 767-780.

[33] Spell, A.W., Kelley, M.L., Wand, J., Self-Brown, S., Davidson, K.L., Pellegrin, A., Palcic, J.L., Meyer, K., Paasch, V. and Baumeister, A. (2008) The Moderating Effects of Maternal Psychopathology on Children's Adjustment Post-Hurricane Katrina. Journal of Clinical Children and Adolescents, 37, 553-563. https://doi.org/10.1080/15374410802148210

[34] Vijayakumar, L., Kannan, G.K. and Daniel, S.J. (2006) Mental Health Status in Children Exposed to Tsunami. International Review of Psychiatry, 18, 507-513. https://doi.org/10.1080/09540260601037581

[35] Wasserstein, S.B. and La Greca, A.M. (1998) Hurricane Andrew: Parent Conflict as a Moderator of Children's Adjustment. Hispanic Journal of Behavioral Sciences, 20, 212-224. https://doi.org/10.1177/07399863980202005

[36] Bernardon, S. and Pernice-Duca, F. (2010) A Family Systems Perspective to Recovery from Posttraumatic Stress in Children. The Family Journal, 18, 349-357. https://doi.org/10.1177/1066480710376618

[37] Scaramella, L.V., Sohr-Preston, S.L., Callahan, K.L. and Mirabile, S.P. (2008) A Test of the Family Stress Model on Toddler-Aged Children's Adjustment among Hurricane Katrina Impacted and Non-Impacted Low-Income Families. Journal of Clinical Children and Adolescents, 37, 530-541. https://doi.org/10.1080/15374410802148202

[38] Birmes, P., Raynaud, J.P., Daubisse, L., Brunet, A., Arbus, C., Klei, R., Cailho, L., Allenou, C., Hazane, F., Grandjea, H. and Schmitt, L. (2009) Children's Enduring PTSD Symptoms Are Related to Their Family's Adaptability and Cohesion. Community Mental Health Journal, 45, 290-299. https://doi.org/10.1007/s10597-008-9166-3

[39] Dyb, G., Jensen, T.K. and Nygaard, E. (2011) Children's and Parents' Posttraumatic Stress Reactions after the 2004 Tsunami. Clinical Child Psychology and Psychiatry, 16, 621-634. https://doi.org/10.1177/1359104510391048

[40] Kelley, M.L., Self-Brown, S., Le, B., Bosson, J.B., Hernandez, B.C. and Gordon, A.T. (2010) Predicting Posttraumatic Stress Symptoms in Children Following Hurricane Katrina: A Prospective Analysis of the Effect of Parental. Journal of Traumatic Stress, 25, 582-590. https://doi.org/10.1002/jts.20573

[41] McKee, T.E., Harvey, E., Danforth, J.S., Ulaszek, W.R. and Friedman, J.L. (2004) The Relation between Parental Coping Styles and Parent-Child Interaction before and after Treatment for Children with ADHD and Oppositional Behavior. Journal of Clinical Child and Adolescent Psychology, 33, 158-168. https://doi.org/10.1207/S15374424JCCP3301_15

[42] Pynoos, R.S. (1994) Traumatic Stress and developmental Psychopathology in 
Children and Adolescents. In: Pynoos, R.S., Ed., Posttraumatic Stress Disorder: $A$ Clinical Review, The Sidran Press. Lutherville, MD, 64-98.

[43] Khamis, V. (2005) Post-Traumatic Stress Disorder among School Age Palestinian Children. Child Abuse and Neglect, 29, 81-95. https://doi.org/10.1016/j.chiabu.2004.06.013

[44] Garfin, D.R., Silver, R.C., Gil-Rivas, V., Guzmán, J., Murphy, J.M., Cova, F., Squicciarini, A.M., George, M. and Guzmán, M.P. (2014) Children's Reactions to the 2010 Chilean Earthquake-The Role of Trauma Exposure, Family Context, and School-Based Mental Health Programming. American Psychological Association, 6, 563-573. https://doi.org/10.1016/j.chiabu.2004.06.013

[45] Tiet, Q.Q., Bird, H.R., Davies, M., Hoven, C., Cohen, P., Jensen, P.S. and Goodman, S. (1998) Adverse Life Events and Resilience. Journal of the American Academy of Child and Adolescent Psychiatry, 37, 1191-1201.

https://doi.org/10.1097/00004583-199811000-00020

[46] Wyman, P.A., Cowen, E.L., Work, W.C. and Parker, G.R. (1991) Developmental and Family Milieu Correlates of Resilience in Urban Children Who Have Experienced Major Life Stress. American Journal of Community Psychology, 19, 405-426.

[47] Davis, L. and Siegel, L.J. (2000) PTSD in Children and Adolescents-A Review and Analysis. Clinical Child and Family Psychology Review, 3, 135-154. https://doi.org/10.1023/A:1009564724720

[48] Gil-Rivas, V., Kilmer, R.P., Hypes, A.W. and Roof, K.A. (2010) The Caregiver-Child Relationship and Children's Adjustment Post-Hurricane Katrina. In: Kilmer, R.P., Gil-Rivas, V., Tedeschi, R.G. and Calhoun, L.G., Eds., Helping Families and Communities Recover from Disaster. Lessons Learned from Hurricane Katrina and Its Aftermath, American Psychological Association, Washington DC, 55-76. https://doi.org/10.1037/12054-002

[49] Gil-Rivas, V., Holman, E.A. and Silver, R.C. (2004) Adolescent Vulnerability Following the September 11th Terrorist Attacks: A Study of Parents and Their Children. Applied Developmental Science, 8, 130-142. https://doi.org/10.1207/s1532480xads0803_3

[50] La Greca, A.M., Silverman, W.K., Vernberg, E.M. and Prinstein, M.J. (1996) Symptoms of Posttraumatic Stress in Children Following Hurricane Andrew. Journal of Consulting and Clinical Psychology, 64, 712-723.

https://doi.org/10.1037/0022-006X.64.4.712

[51] Pynoos, R.S., Steinberg, A.M. and Wraith, R. (1995) A Developmental Model of Childhood Traumatic Stress. In: Cicchetti, D. and Cohen, D.J., Eds., Developmental Psychopathology, Vol. 2: Risk, Disorder, and Adaptation, John Wiley and Sons, Oxford, 72-95.

[52] Salmon, K. and Bryant, R.A. (2002) Posttraumatic Stress Disorder in Children: The Influence of Developmental Factors. Clinical Psychology Review, 22, 163-188. https://doi.org/10.1016/S0272-7358(01)00086-1

[53] McFarlane, A.C. and Yehuda, R. (2000) Clinical Treatment of Posttraumatic Stress Disorder: Conceptual Challenges Raised by Recent Research. Australian and New Zealand Journal of Psychiatry, 940-953. https://doi.org/10.1080/000486700268

[54] Hinton, D.E. and Lewis-Fernández, R. (2011) The Cross-Cultural Validity of Posttraumatic Stress Disorder: Implications for Dsm-5. Depression and Anxiety, 28, 783-801. https://doi.org/10.1002/da.20753

[55] Almedom, A. and Summerfield, D. (2004) Mental Wellbeing in Settings of Complex Emergency: An Overview. Journal of Biosocial Science, 36, 381-388. 
https://doi.org/10.1017/S0021932004006832

[56] McHugh, P. and Treisman, G. (2007) PTSD: A Problematic Diagnostic Category. Journal of Anxiety Disorders, 21, 211-222.

https://doi.org/10.1016/j.janxdis.2006.09.003

[57] Miller, K.E., Omidian, P., Kulkarni, M., Yzqubi, A., Daudzai, H. and Rasmussen, A. (2009) The Validity and Clinical Utility of Post-Traumatic Stress Disorder in Afghanistan. Transcult Psychiatry, 46, 219-237.

https://doi.org/10.1177/1363461509105813

[58] Bisson, S.S. (2013) What Happened to Harmonization of the PTSD Diagnosis: The Divergence of ICD11 and DSM5. Epidemiology and Psychiatric Sciences, 22, 205-207. https://doi.org/10.1017/S2045796013000164 